\title{
PENGARUH DEFORMASI BERTAHAP ROLLING TERHADAP KEKERASAN BAJA TAHAN KARAT AUSTENITIK 304 UNTUK KEPERLUAN KONSTRUKSI
}

\author{
Juwarin, MOS Aritonang, Dadang Suyadi S
}

\begin{abstract}
Abstrak
Penelitian ini bertujuan untuk mendapatkan data secara empirik tentang pengaruh deformasi bertahap rolling terhadap nilai kekerasan baja tahan karat Austenitik 304 untuk keperluan konstruksi.

Metode yang digunakan dalam penelitian ini adalah eksperimental. Kelompok eksperimen adalah 3 perlakuan, yakni: deformasi rolling 12\%, $25 \%$ dan $50 \%$.

Instrumen penelitian adalah mesin uji kekerasan Brinell, mesin rolling untuk proses deformasi dan mikroskop elektron untuk pengujian metalografi.Uji persyaratan analisis yang digunakan adalah uji Chi Kuadrat untuk data normalitas dan homogenitas. Pengujian metalografi menunjukkan adanya perbedaan yang spesifik antara struktur logam pada masing-masing spesimen yang mengalami deformasi rolling setelah pengujian kekerasan bahan.

Hasil penelitian adalah terdapat pengaruh deformasi bertahap rolling terhadap nilai kekerasan bahan bagi keperluan konstruksi.
\end{abstract}

Kata Kunci: baja tahan karat

\section{PENDAHULUAN}

Baja adalah suatu bahan dengan sama besar, terdiri atas Ferrum Fe dalam bentuk hublur dan 0,04-1,6\% zat Carbon yang didapat dengan jalan membersihkan bahan pada temperatur sangat tinggi dengan menggunakan beberapa proses dari sebagian besar besi kasar, di hasilkan oleh dapur tanur tinggi. [Potma,A.P. dan De Vries,J.E.,1991, h.21]

Secara umum terdapat 3 jenis baja tahan karat, yaitu: baja tahan karat feritik, baja tahan karat martensitik, baja tahan karat Austenitik dan baja tahan karat precipitation hardening PH paduannya. Diantara keempat jenis baja tahan karat tersebut, y ang sering di gunakan adalah tiga tipe yang pertama.

\begin{tabular}{|lcr|}
\hline Juwarin & MOS Aritonang, Drs & Dadang Suyadi S. Drs. MPd \\
Alumni Jurusan Teknik Sipil & Staf Pengajar Jurusan Teknik Sipil & Staf Pengajar Jurusan Teknik Sipil \\
Fakultas Teknik & Fakultas Teknik & Fakultas Teknik \\
Universitas Negeri Jakarta, 13220 & Universitas Negeri Jakarta, 13220 & Universitas Negeri Jakarta, 13220 \\
& & \\
& & \\
\hline
\end{tabular}

Jurnal Menara Jurusan Teknik Sipil FT.UNJ

Volume III No.2 - Juli 2008 
Pada penelitian ini spesimen yang dipakai adalah baja tahan karat Austenitik 304. Baja tipe ini lebih baik karena sifat mampu las weldability) yang lebih baik dan ketahanan korosi yang lebih baik dari baja anti karat jenis feritik dan martensitik.

Baja tahan karat Austenitik lebih tahan karat dibanding dengan baja tahan karat martensitik dan feritik. Hal ini disebabkan baja tahan karat Austenitik memiliki kadar khrom yang lebih besar. Unsur khrom ini membentuk lapisan lindung khrom Oksida Cr2O3 pada permukaan sehingga tahan karat.

Pada penelitian ini spesimen yang dipakai adalah baja tahan karat Austenitik 304. Baja tipe ini lebih baik karena sifat mampu las weldability) yang lebih baik dan ketahanan korosi yang lebih baik dari baja anti karat jenis feritik dan martensitik.

Baja tahan karat Austenitik lebih tahan karat dibanding dengan baja tahan karat martensitik dan feritik. Hal ini disebabkan baja tahan karat Austenitik memiliki kadar khrom yang lebih besar. Unsur khrom ini membentuk lapisan lindung khrom Oksida Cr2O3 pada permukaan sehingga tahan karat.

Fasa adalah bagian dari sistem yang homogen secara fisis. Pada baja apabila mendapat perlakuan keras menyebabkan perubahan struktur. Baja Tahan Karat Austenitik mempunyai kekuatan statik dan dinamik, ulet, mudah diolah, tahan korosi dan mempunyai sifat elektromagnet agar dapat dipakai sebagai bahan untuk konstruksi.

Kekerasan hardness didefinisikan sebagai ketahanan bahan terhadap penetrasi pada permukaannya. Prinsip percobaan pada uji kekerasan adalah ketahanan material tersebut terhadap gaya penekanan dari material lain yang lebih keras. Penekanan tersebut dapat berupa makanisme penggesekan stratching, pantulan ataupun indentasi penekanan den gan bola baja keras dari material keras terhadap suatu permukaan benda uji. Metode indentasilah yang banyak digunakan pada percobaan sampel yang kecil, dan umumnya berupa metode Brinell, Vickers dan Rockwell.

Pada baja tahan karat Austenitik 304 mempunyai karakteristik terhadap kekuatan tariktensile strenght, kekuatan luluhyield strenght dan pertambahan panjangelongation strength. [ASM International, 1996, h.46.]

Pengaruh Deformasi Bertahap Rolling terhadap Kekerasan Baja Tahan Karat Austenitik 304 untuk Keperluan Konstruksi, Juwarin, MOS Aritonang,Dadang Suyadi S 
Tabel 1 : Karakteristik baja tahan karat Austentik 304

\begin{tabular}{|c|c|c|}
\hline Hardness & Rockwell Hard & $81 \mathrm{HRB}$ \\
\hline Tensile Strength & Mpa & 586 \\
\hline Yield Strength & $0,2 \%$ & $241 \mathrm{Mpa}, 35 \mathrm{Ksi}$ \\
\hline Reductin of Area & $\%$ & 70,0 \\
\hline Elongation & $\ln 50,8 \mathrm{~mm} \%$ & 60 \\
\hline
\end{tabular}

Karena nilai kekerasan pada HRB, maka dikonversikan ke dalam daftar Brinell sesuai dengan Brinell Hardness Number and Conversion Table Ha nd Book of Metalurgi, h.29

Tabel 2. Nilai Kekerasan pada HRB

\begin{tabular}{|c|c|c|c|c|}
\hline HRB & HBN & PKg & D(mm & dmm \\
\hline 81 & 146 & 3000 & 10 & 4,95 \\
\hline 81 & 146 & 750 & 5 & 2,475 \\
\hline 81 & 146 & 187,5 & 2,5 & 1,236 \\
\hline
\end{tabular}

Jika sebuah Gaya dikerjakan pada sebuah batang menyebabkan batang tersebut berubah bentuk mengalam i deformasi. Deformasi yang dialami oleh sampel besi baja tahan karat Austenitik 304 adalah deformasi plastis, karena prinsip dasar pengerjaan logam adalah melakukan perubahan bentuk pada benda kerja dengan cara memberikan gaya luar.

Menurut hukum Hooke: [Lawrenceh,\& Van Vlack 1995, h.8]

$$
\sigma=E . \in
$$

Ini adalah hukum dasar Elastisitas. E disebut modulus eelastisitas dan merupakan sifat tiap-tiap bahan. Jika bahannya berbeda, maka akan didapatkan sebuah perilaku elastis dengan modulus elastisitas $\mathrm{E}$ yang berbeda pula. 


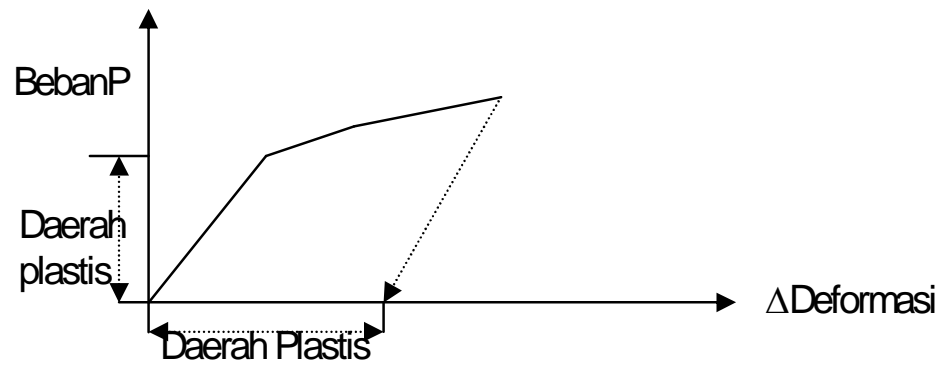

Gambar 1.Diagram Deformasi.

Sumber: Drs. Daryanto, Mekanika BangunanJakarta: Bumi Aksara, 1994, h.3.

Pada deformasi yang akan dilakukan terhadap benda uji, menggunakan penempaan rol. Batang besi yang pendek dikecilkan penampangnya dengan mesin rolling. Akibat dari deformasi yang bertahap menyebabkan perubahan bentuk serta mengalami perubahan ketebalan dan nilai kekerasan dari benda uji.

Konstruksi berasal dari bahasa belanda $c$ onstructie yang artinya struktur dan dari bahasa Inggris constrution yang artinya pembangunan.

Proses konstruksi suatu bangunan pada hakekatnya merupakan rangkaian kegiatan-kegiatan yang berdasarkan pada sistem rekayasa engineering system konstruksi, yang bersifat unik atau khas untuk setiap proyek.

Baja konstruksi mencakup $90 \%$ dari seluruh pembuatan baja. Baja konstruksi digunakan untuk pembuatan batang baja, baja profil untuk segala jenis konstruksi jembatan, menara, bangunan tinggi, baja be ton, lembar-lembar, pipa, kawat dan bagian mesin yang terbuat dari baja dituang, ditempa, dikempa.

Atas dasar itulah, maka perlu dilakukan suatu penelitian yang mampu menjelaskan secara konseptual dan operasional terhadap kekerasan apabila mendapat perlakuan berupa deformasi bertahap.

Berdasarkan kajian teori dan kerangka berpikir yang telah diuraikan di atas, maka dapat dirumuskan hipotesis sebagai berikut: Terdapat pengaruh yang signifikan deformasi bertahap rolling terhadap kekerasan pada baja tahan karat Austenitik 304 untuk keperluan konstruksi.

Pengaruh Deformasi Bertahap Rolling terhadap Kekerasan Baja Tahan Karat Austenitik 304 untuk Keperluan Konstruksi, Juwarin, MOS Aritonang,Dadang Suyadi S 


\section{METODA}

Metoda yang akan dipergunakan dalan penelitian ini adalah metoda eksperimental. Metoda eksperimental adalah metode yang bertujuan untuk menyelidiki ada tidaknya hubungan sebab-akibat serta berapa besar hubungan sebab-akibat tersebut dengan cara memberikan perlakuan-perlakuan tertentu pada beberapa kelompok eksperimen dan menyediakan kontrol untuk perbandingan. [Nazir,Moh., 1988,h.75]. Pengujian yang dilakukan meliputi uji keras bertujuan untuk mengetahui derajat kekerasan dari suatu logam.

Pengertian umum kekerasan ialah penolakan suatu badan bahan melawan desakan suatu badan lainnya. Derajat kekerasan diungkapkan dalam angka kekerasan yang berlainan untuk setiap cara. Pengujian kekerasan memiliki keunggulan berupa kenyataan bahwa disini benda yang diuji tidak dihancurkan. Percobaan uji kekerasan brinell sesuai dengan standar SNI-19-0405-1989-Ed 1-3.

Pengujian metalografi bertujuan untuk mengetahui perubahan yang terjadi pada setiap sampel setelah mendapat beberapa perlakuan, seperti pemanasan dan pendinginan serta deformasi rolling.Dalam pengujian ini sesuai dengan standar SNI 07-1333-1989 Ed $1-3$.

Standar spesimen uji yang digunakan adalah normalisasi Belanda N 713,yaitu :

Tabel 1.Tebal baja pada pengujian kekerasan Brinell.

\begin{tabular}{|c|c|c|c|}
\hline Tebal Benda Percobaan & Diatas $\mathbf{6 ~ m m}$ & $\mathbf{6 - 3} \mathbf{~ m m}$ & Dibawah $\mathbf{3 m m}$ \\
\hline Garis Tengah Peluru & $10 \mathrm{~mm}$ & $5 \mathrm{~mm}$ & $2,5 \mathrm{~mm}$ \\
\hline Beban dari Peluru & $3000 \mathrm{~kg}$ & $750 \mathrm{~kg}$ & $187,5 \mathrm{~kg}$ \\
\hline
\end{tabular}

Bentuk spesimen yang digunakan dalam percobaan ini tidak ada bentuk standar atau ukuran pada uji kekerasan Brinell [Standar ASTM, 1993].

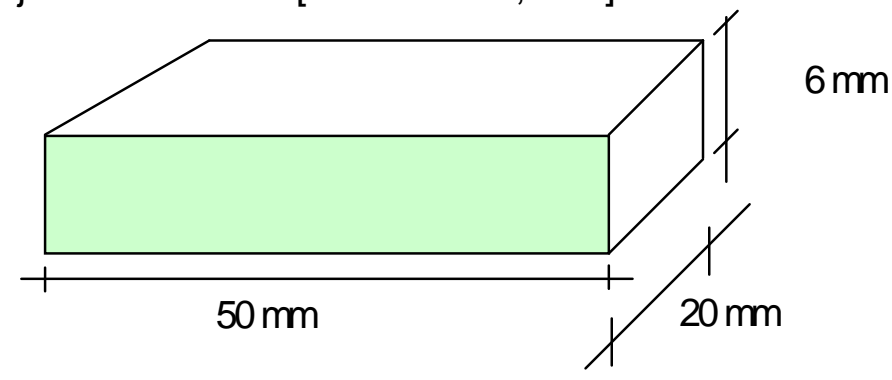

Gambar 2. Sampel untuk Uji Kekerasan Brinell 


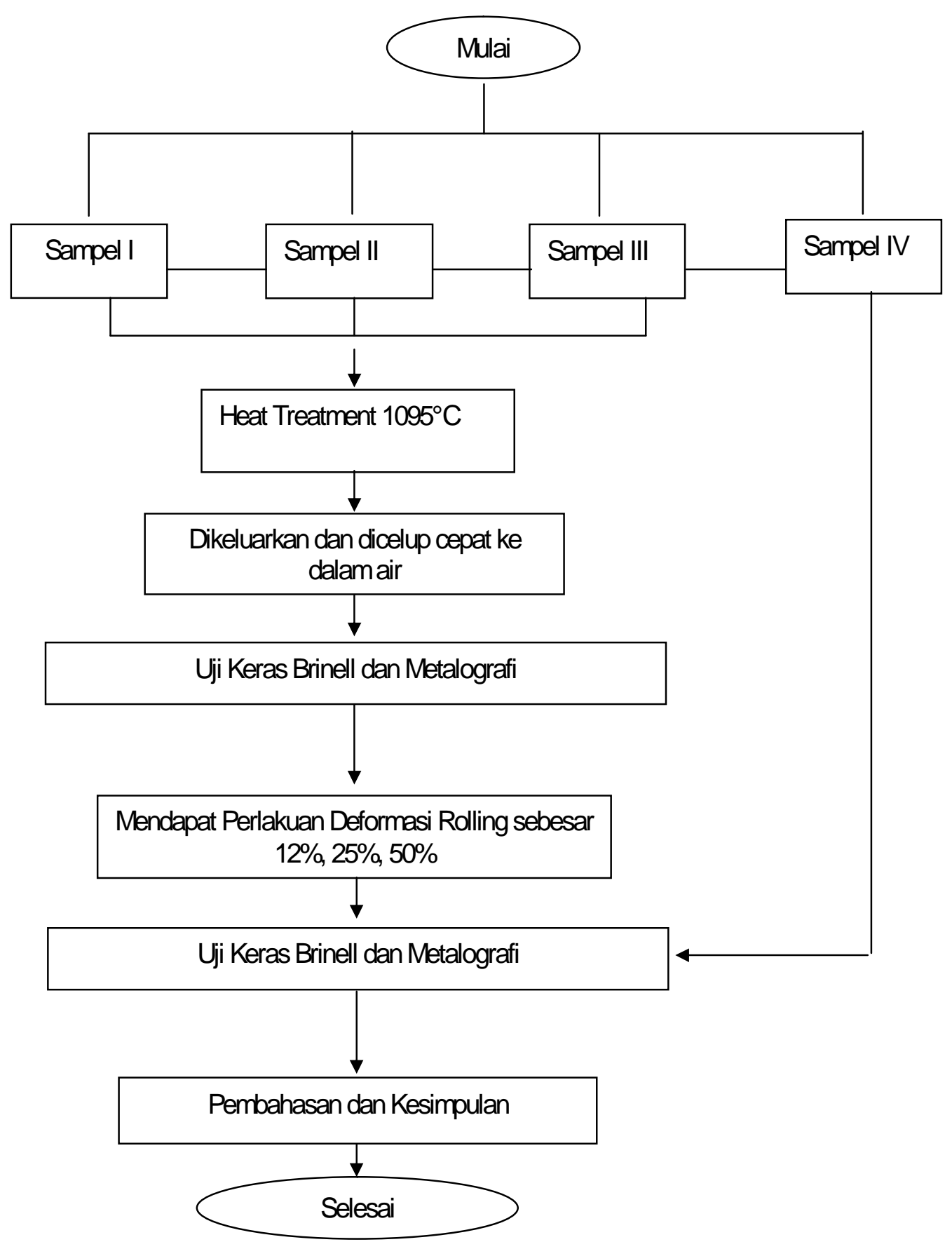

Gambar 3. Skema Langkah percobaan penelitian 
Persyaratan yang harus dipenuhi sebelum sampai pada analisis data antara lain adalah uji normalitas dan uji homogenitas.

\section{HASIL DAN PEMBAHASAN}

\section{Hasil}

1. Hasil nilai rata-rata kekerasan Brinell Baja Tahan Karat Austenitik 304 pada sampel IV, sebanyak 3 spesimen adalah :148,863 Kg/mm².

2. Hasil rata-rata nilai kekerasan Brinell pada sampel I,II III, setelah mendapat perlakuan Heat Tretment dan Quenching,sebanyak 9 spesimen adalah 146,115 kg/mm².

3. Hasil rata-rata nilai kekerasan Brinell pada sampel I setelah mendapat perlakuan deformasi rolling sebesar $12 \%$, sebanyak 3 spesimen adalah $154,765 \mathrm{~kg} / \mathrm{mm}^{2}$.

4. Hasil rata-rata nilai kekerasan Brinell pada sampel II setelah mendapat perlakuan deformasi rolling sebesar 25\%, sebanyak 3 spesimen adalah $161,399 \mathrm{~kg} / \mathrm{mm}^{2}$.

5. Hasil rata-rata nilai kekerasan Brinell pada sampel III setelah mendapat perlakuan deformasi rolling sebesar 50\%, sebanyak 3 spesimen adalah $165,301 \mathrm{~kg} / \mathrm{mm}^{2}$.

Dalam pengujian eksperimen murni ini digunakan uji normalitas Chi Kuadrat $\mathrm{X}^{2}$ hitung $=4,7$. Dari daftar distribusi Chi Kuadrat dengan derajat kebebasan $\mathrm{dk}=1$ dengan taraf nyata $\alpha=0.01$ diperoleh nilai $X^{2} 0,991=6,63$ sehingga $X \quad{ }^{2}$ hitung $<X^{2}$ tabel. Hipotesis nol diterima dan populasi berdistribusi normal.

Dalam penelitian eksperimen murni ini digunakan uji homogenitas bartlett didapat nilai $X^{2}$ hitung $=3,4217$.

Berdasarkan daftar distribusi chi kuadrat dengan $\mathrm{dk}=2$ dan taraf nyata adalah 0,01 maka didapat: $X^{2} 0,992=9,21$. Jadi, $X \quad$ 2hitung $<x^{2}$ tabel atau $X^{2}$ hitung $<X^{2} 0,992$.

Sehingga hipotesis $H_{0}: \alpha_{1}{ }^{2}=\alpha_{2}{ }^{2}=\alpha_{3}{ }^{2}$ diterima dalam taraf nyata 0,01 dan varians bersifat homogen.

Pengujian hipotesis digunakan uji Anava, maka dibuatlah daftar data sampel dari 9 buah spesimen yang telah diuji kekerasan bahannya yang telah melalui deformasi rolling. 
Fhitung $=\frac{85,125}{1,4266}=59,67$. Dengan taraf signifikan 0,01 ,dk pembilang 2 dan penyebut adalah 6 maka nilai untuk F0,992 adalah 10,92. Sehingga didapatkan Fhitung $>$ Ftabel berarti Ho ditolak dan menerima $\mathrm{Hi}$.

Dengan demikian hasil penelitian menunjukkan bahwa ketiga perubahan deformasi rolling tersebut memberikan pengaruh terhadap uji kekerasan bahan.

Jadi, hipotesis Ho: $\mu_{1}=\mu_{2}=\mu_{3}$ diterima dengan taraf nyata 0,01 . Ketiga macam deformasi bertahap tersebut menyebabkan nilai kekerasan menjadi bertambah besar. Dengan kata lain, ketiga perlakuan deformasi rolling tersebut sama efektifnya dan akan memberikan hasil yang secara nyata tidak berbeda bagi keperluan konstruksi.

\section{Pembahasan}

Secara umum, proses deformasi bertahap rolling memberikan pengaruh terhadap nilai kekerasan baja. Oleh karena itu pengaturan metode, suhu pemanasan dan pendinginan yang tepat akan menentukan karakteristik sifat dan struktur bahan yang dihasilkan.

Karakteristik dan struktur bahan yang dihasilkan dapat menentukan terjadinya ketangguhan, maupun keuletan bahan. Hasil tersebut dapat dilihat berdasarkan semakin tinggi deformasi rolling, semakin rapat butiran fasa yang dihasilkan. Sebaliknya, bila butiran fasa menjauh maka akan dihasilkan suatu kekerasan dan kekuatan tarik yang semakin rendah.

Pengaturan metode bertujuan untuk mempermudah percobaan tersebut. Suhu pemanasan dan pendinginan cepat akan menentukan terjadinya peretakan ulet pada bahan.

Sedangkan upaya untuk mengatasi agar proses deformasi bertahap rolling tepat terhadap sifat keuletan dan ketangguhan bahan, maka digunakan suhu pemanasan dalam dapur pemanas pada suhu $1095^{\circ} \mathrm{C}$ selama 1 jam untuk menghomogenkan struktur bahan,sedangkan untuk pendinginan cepat, digunakan air dengan suhu $4-9^{\circ} \mathrm{C}$.

Pengaruh Deformasi Bertahap Rolling terhadap Kekerasan Baja Tahan Karat Austenitik 304 untuk Keperluan Konstruksi, Juwarin, MOS Aritonang,Dadang Suyadi S 


\section{KESIMPULAN}

Proses deformasi bertahap rolling ini dapat menghasilkan suatu nilai kekerasan yang semakin meningkat. Sedangkan kuat tarik juga semakin tinggi berdasarkan kerapatan pada photo pengujian metallugrafi dan brinell hardness number and convertion table, dengan ketentuan pendinginan cepat ke dalam air quenching .

Berdasarkan kepada hasil penelitian, maka dapat disajikan saran sebagai berikut:

1. Dalam proses perlakuan panas bahan perlu diperhatikan segi karakteristik sifat bahan yang akan dipanaskan, pemilihan metode, suhu pemanasan dan pendinginan yang tepat.

2. Dalam menentukan nilai kekerasan bahan diperlukan kecermatan dan ketelitian dalam pengamatan pada jarum penunjuk beban penekan yang dihasilkan.

3. Perlu diadakan penelitian lanjutan mengenai pengaruh deformasi bertahap rolling terhadap nilai kekerasan bagi keperluan konstruksi plambing pada bahan yang berlainan dan sampel dengan jumlah yang lebih banyak.

4. Perlu diupayakan suatu alternatif bahwa baja tahan karat Austenitik 304 sebagai bahan yang bagus dan sangat penting bagi keperluan konstruksi plambing, terutama pada pemakaian di dalam tanah dan tempat yang sering menimbulkan sifat korosif.

\section{DAFTAR PUSTAKA}

American Standar for Testing Material ASTM .1993.

ASM Speciality. Hand Book of Stainless Steels. ASM International Hand Book-Commite, Januari, 1996

Daryanto, Drs. Mekanika Bangunan, Jakarta: Bumi Aksara, 1994

Nasir, Moh. Metode Penelitian.Jakarta: Ghalia Indonesia, 1988.

Potma,A.P.,\& De Vries,J.E. Konstruksi Baja: Teori, Perhitungan dan Pelaksanaan, terjemahan Hendardji Jakarta: Pradnya Paramita, 1991.

Vlack,Van,\& H.,Lawrence. IImu dan Teknologi Bahan. terjemahan Sriati Djaprie, Jakarta: Aerlangga, 1995 
ISSN: $1907-4360$

Standar ASTM, 1993, Metals Test Methods and Analytical Procedures.Annual Book of ASTM Standard

Pengaruh Deformasi Bertahap Rolling terhadap Kekerasan Baja Tahan Karat Austenitik 304

untuk Keperluan Konstruksi, Juwarin, MOS Aritonang,Dadang Suyadi S 